\title{
Electronic Description of Few Selected Flavonoids by Theoretical Study
}

\author{
M.Rajendran \\ Associate Professor \\ Research and Postgraduate \\ Department of Chemistry \\ N.M.S.S.Vellaichamy Nadar \\ College, Madurai-625 019, \\ Tamilnadu, India
}

\author{
R.Ravichandran \\ Research and Postgraduate \\ Department of Chemistry \\ N.M.S.S.Vellaichamy Nadar \\ College, Madurai-625 019, \\ Tamilnadu, India
}

\author{
D.Devapiriam \\ Associate Professor \\ Research and Postgraduate \\ Department of Chemistry \\ N.M.S.S.Vellaichamy Nadar \\ College, Madurai-625 019, \\ Tamilnadu, India
}

\begin{abstract}
The electronic properties responsible for free radical scavenging and metal chelation of a set of 7 flavonoids compounds were studied. Electronic parameters were calculated using semi empirical PM3 method. The structure activity relationship of $\mathrm{OH}$ substitution, $\mathrm{C} 2-\mathrm{C} 3$ double bond, chelation site of flavonoid and related property of antioxidant efficiency, BDE, mulliken atomic charge, electron current movement among $\mathrm{A}, \mathrm{B}$ and $\mathrm{C}$-rings were investigated. The relative change in energy $\left(\Delta \mathrm{H}_{\mathrm{f}}\right)$ associated with the formation of phenoxyl radicals and spin density distribution of phenoxyl radicals were determined. The complexation mechanism of seven flavonoids quercetin, morin, apigenin, naringenin, chrysin, taxifolin and fisetin with metal ions, by molecular mechanics (UFF) method was investigated. Flavonoids metal chelation site order on toxic metals $\mathrm{Pb}, \mathrm{Bi}$ and $\mathrm{Cd}$ was investigated. The most likely chelation site for metal ion was $5-\mathrm{OH} \& 4=\mathrm{O}$ group, followed by $4=\mathrm{O} \& 3-\mathrm{OH}$ group and the 3'\& 4' hydroxyl for all the flavonoid molecules studied. In the absence of C2-C3 double bond (taxifolin) the order of metal chelation site with metal was $3-\mathrm{OH} \& 4=\mathrm{O}$, followed by $5-\mathrm{OH}$ \& 4=O group and 3' \& 4' hydroxyl.
\end{abstract}

\section{Keywords}

Free radical, antioxidants, flavonoid-Metal complex, PM3 method.

\section{INTRODUCTION}

Flavonoids are common polyphenolic radical scavengers that commonly occur in plants. This class of compounds includes flavones, isoflavones and the 2,3-dihydro derivatives of flavones, namely flavonones, which are interconvertible with the isomeric chalcones [1]. They are naturally synthesized by the secondary metabolism of plants. One of the most remarkable properties of flavonoids rises from their behaviour as antioxidants acting through a variety of ways, including direct inhibition of formation or activity of reactive oxygen species and interaction, inhibition, with enzyme [2,3]. The study of flavonoids is therefore of great practical and theoretical importance. Thus, the detailed knowledge of their molecular structures, both from energetic and geometric view points, is of great importance to gain a deeper insight into their possible therapeutic applications. Computational chemistry methods are one of the most powerful tools to achieve advances in this field, and several studies may be found in the literature $[4,5]$.

A great number of flavonoids, especially flavones, can efficiently chelate metals. Metal complexation reactions play important and multiple roles in biological systems and provide in vivo sensitive colour stabilization mechanisms in plants [6]. Metal complexation reactions enhance protection of plants from pathogens and plant eaters. By chelating metal ions, flavonoids generally prevent metal-catalyzed free radical generation and their subsequent reactions and accordingly protect very important biologically active molecules from oxidative system [7].

In general, radical scavenging by flavonoids occurs via electron donation from the free hydroxyls on the flavonoid nucleus with the formation of less reactive flavonoid aroxyl radicals $[8,9]$. The phenolic groups are also responsible of the metal-chelating activity. In fact it is to be considered that $\mathrm{O}_{2}{ }^{-}$ and $\mathrm{H}_{2} \mathrm{O}_{2}$ in the presence of transition metals such as iron and copper may be converted into highly reactive ${ }^{\circ} \mathrm{OH}$. Flavonoids may sequester these metal ions by chelation and preventing the metal-mediated generation of harmful oxidizing radicals, may protect the potential biological targets from oxidative stress $[10,11]$.

There are three possible metal complexing domains that can interact with metal ions: the 3',4'-dihydroxy group located on the $\mathrm{B}$ ring and the 3 or 5 -hydroxy and 4-carbonly group in the $\mathrm{C}$ ring. A relatively large number of publications have appeared in which several complexing mechanisms and spatial structures are proposed for metal-flavonoid compounds [12].

The purpose of this study was to better elucidating molecular aspects of beneficial effect of flavonoids, to obtain the preference position of flavonoids in binding metal ions. Our aim is to individually study the capacity of complexation of each flavonoids with metals theoretically using semiempircal PM3 method. The highest binding energy clearly identifies the 3-hydroxyl-4-carbonyl group as the most probable chelation site for metal ion, followed by 4-carbonly-5hydroxyl and 3',4'-hydroxyl groups [13]. In the earlier study mulliken atomic charges are calculated by semiempirical method, and their values are correlated with antioxidant efficiency of flavones [14].

\section{COMPUTATIONAL METHOD}

ArgusLab [15] provides molecular modeling functionality that does not utilize the concept of a Z-matrix. Another useful feature is the ability to add hydrogen atoms and molecular mechanics-based cleaning of geometry at each step of structure building. Due to the implementation of the UFF (Universal Force Field), ArgusLab has the ability to handle the entire periodic table. Besides the molecular mechanics, geometry optimization or single-point energy calculations can be performed with semiempirical methods (EHT, PM3, AM1, 
MNDO). Additionally, the ZINDO method parameterized specially to predict the excited state properties allows the electronic excitation spectra to be modeled. From semiempirical calculations, electron density is derived and may further be displayed. The visualization of molecular orbitals is provided and the electrostatic potential can be calculated and mapped on to the electron density surface. Although these techniques are reasonably fast on a PC computer, the results are lacking in accuracy and need to be treated on a qualitative basis rather than in a quantitative manner. Similarly, the molecular mechanics approach employing UFF is good for cleaning up structures when sketched in the builder and for reining the initial geometries before using more expensive methods. The molecular mechanics method calculates the energy as the function of the coordinates and energy minimization is an integral part of the method.

The flavonoid structure was generated by ArgusLab 4.0 and geometry optimization was performed with the semi-empirical RHF/ PM3 parameterization (Dewar et al., 1985) [16]. The minimum potential energy is calculated by using geometry convergence function. Surfaces created to visualize ground state properties as well as excited state properties such as orbital electron densities, electrostatic potentials (ESP), spin densities and generated the grid data, used to make molecular orbital surfaces and visualized the molecular orbitals. All geometry optimizations are performed without any symmetry constraints. Geometry optimization is followed by singlepoint calculation using PM3 method. The ability of flavonoid antioxidants to donate a hydrogen atom is mainly governed by the BDE value of $\mathrm{O}-\mathrm{H}$ bond. The BDE of $\mathrm{OH}$ bond can be calculated by the following equation [17].

$$
\mathrm{BDE}(\mathrm{Fl}-\mathrm{OH})=\Delta_{\mathrm{f}} \mathrm{H}(\mathrm{Fl}-\mathrm{O} \bullet)+\Delta_{\mathrm{f}} \mathrm{H}(\mathrm{H})-\Delta_{\mathrm{f}} \mathrm{H}(\mathrm{Fl}-\mathrm{OH})
$$

Where $\Delta_{\mathrm{f}} \mathrm{H}(\mathrm{Fl}-\mathrm{O} \bullet)$ is the enthalpy of formation of the flavonoid phenoxyl radical generated after $\mathrm{H}^{\cdot}$ abstraction, $\Delta_{\mathrm{f}} \mathrm{H}$ $(\mathrm{H})$ is the enthalpy of formation of the hydrogen atom and $\Delta_{\mathrm{f}} \mathrm{H}(\mathrm{Fl}-\mathrm{OH})$ is the enthalpy of formation of the parent flavonoid molecule.

For metal cation, as well as their metal-flavonoid complexes, the geometries configurations are optimized and the lowest energy structures are chosen for further analysis. The metalflavonoid binding energies are calculated at MM (UFF) levels in gas phase. The earlier published experimental results find that flavonoids often deprotonate to form $(\mathrm{M}-\mathrm{O})^{-}$, then the anion interact with metal cations to form coordination complexes [18]. Thus in this study, the metal-flavonoid complexes are obtained by interaction of metal cations with the corresponding anion formed by $\mathrm{O} 3$ \& $\mathrm{O} 5$ and $\mathrm{O} 3$ ' \& O4' deprotonation, including $\mathrm{O} 3, \mathrm{O}^{-}$and $\mathrm{O} 5, \mathrm{O}^{-}$.

\section{RESULTS AND DISCUSSION}

\subsection{HOMO \& LUMO and structure property relationship}

To determine the theoretical antioxidant efficiencies of flavonoids, various positions of hydroxyl substitution and C2-C3 double bond was first selected for this study. The chemical structure of these compounds is presented in the figure-1. Since $\pi$ electron configuration is of great importance in understanding the antioxidant capacity of polyphenols, the selected flavonoids should have various structural features. Figure-2 showed the HOMO and LUMO frontier orbitals of the optimized structure and their charge distribution among the atoms in the molecule. In the absence of $\mathrm{C} 2-\mathrm{C} 3$ double bond, the conjugation was restricted over the entire molecule, as compared to quercetin. Thus in taxifolin, the HOMO and LUMO were strongly separated on the $\mathrm{B}$ and A-ring, respectively (figure-2). This lack of conjugation leads to strong hypsochromic shift of the main absorption band near the visible region (e.g at $370 \mathrm{~nm}$ like for quercetin); thus taxifolin is colourless in solution [19].

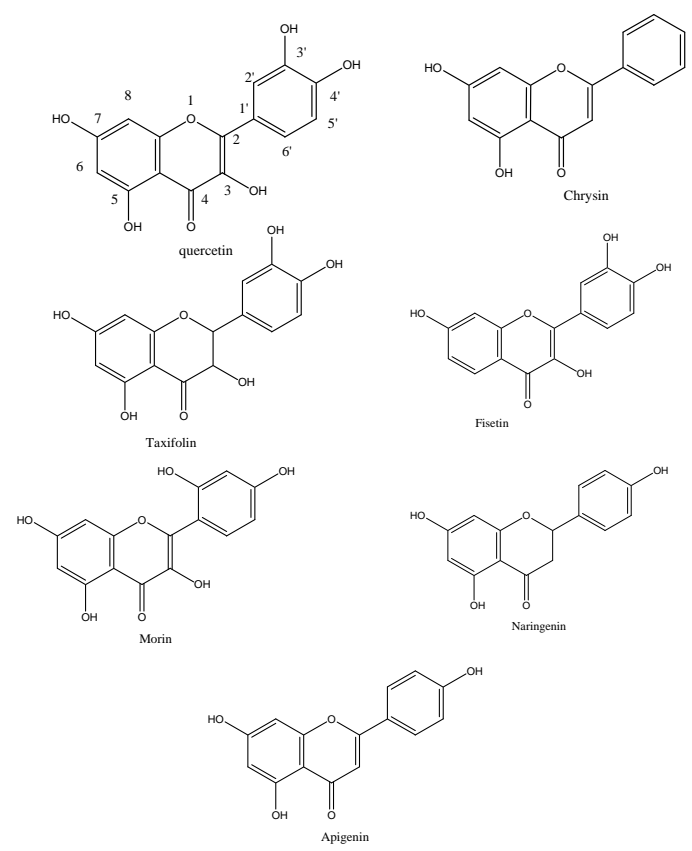

Fig-1 Chemical structure of flavonoids

\subsection{UV-Vis spectra and structure activity relationship}

The absorption wavelengths of numerous polyphenols depend on number and position of $\mathrm{OH}$ groups. When increasing the number of $-\mathrm{OH}$ groups in the B-ring of flavonoids, the experimental $\lambda_{\max }$ is systematically red shifted. This is due to mesomeric $(+\mathrm{M})$ effect of hydroxyl group, which extends the $\pi$-conjugation in the frontier orbital (figure-2). Consequently, this induces a bathochromic shift, which is formed from the delocalization of MOs, thus rationalizing the experimental results. UV-Vis spectra of flavonoids exhibit at least two absorption bands, one (Band I) ranging from 240 to $280 \mathrm{~nm}$ and another (Band II) from 300 to $400 \mathrm{~nm}$ [20].

In dihydroflavonols, e.g taxifolin, the absence of C2-C3 double bond destroys the conjugation over the entire molecule, as compared to flavonols, e.g quercetin. Thus, in taxifolin, the HOMO and LUMO are strongly separated on the $\mathrm{B}$ and A rings, respectively (figure 2). Absence of conjugation leads to lowering of wavelength of the main absorption band. For example quercetin exhibits absorption at $379 \mathrm{~nm}$, but for taxifolin it appears at $326 \mathrm{~nm}$. Another peak for A-ring was at $320 \mathrm{~nm}$ for quercetin, but at $324 \mathrm{~nm}$ for taxifolin. C-ring peak was not observed for taxifolin, but for quercetin C-ring peak observed at $270 \mathrm{~nm}$. Similar to taxifolin absorbance behavior, naringenin also shows peak at $322 \mathrm{~nm}$ and $225 \mathrm{~nm}$ for B-ring and A-ring respectively (Table 7).

The number and position of $\mathrm{OH}$ groups, sensitively influences the absorption wavelengths. For example the $\lambda_{\max }$ value was $392 \mathrm{~nm}, 379 \mathrm{~nm}, 371 \mathrm{~nm}, 357 \mathrm{~nm}$ and $350 \mathrm{~nm}$ for morin (five 
$\mathrm{OH}$ groups), quercetin (five $\mathrm{OH}$ groups), fisetin (four $\mathrm{OH}$ groups), apigenin (three $\mathrm{OH}$ groups) and chrysin (Two $\mathrm{OH}$ groups) respectively [20]. The absorption wavelength is affected by the chemical structure that is conjugation, number and position of substituent. Rice-Evans et al., suggested that an increase in the number of $\mathrm{OH}$ or $\mathrm{CH}_{3}$ substituent leads to a bathachromic (red) shift [21]. This is due to the mesomeric (+M) effect the hydroxyl group which extends the $\pi$ conjugation in the frontier orbitals, as can be seen from our PM3 calculation in fig- 2 . In the presence of $\mathrm{C} 2-\mathrm{C} 3$ double bond (flavones and flavonols) the band is assigned to HOMO to LUMO transition. In the absence of the $\mathrm{C} 2-\mathrm{C} 3$ double bond this transition becomes completely forbidden, due to complete orbital separation.

\subsection{Role of C2-C3 double bond}

The absence of C2-C3 double bond in dihydroflavonoids (e.g taxifolin) and flavonones substantially reduces the conjugation as compared to flavonols (e.g quercetin) and flavones, and this induces hypsochromic shift. In fact, the shift is due to the loss of the main absorption band observed in flavones and flavonols. In flavonones and dihydroflavonols, this transition becomes completely forbidden, due to complete orbital separation (figure 2).

The molecular structure of flavonoid family is characterized by the large charge delocalization spreading along the studied molecules from $\mathrm{A}$ to $\mathrm{B}$ ring through the $\mathrm{C}$ one. The coplanarity of ring $\mathrm{A}, \mathrm{B}$ and $\mathrm{C}$ are maintained in the presence of $\mathrm{C} 2-\mathrm{C} 3$ double bond (figure 2). In the absence of $\mathrm{C} 2-\mathrm{C} 3$ double bond in the flavonoid the rings should not be planar (figure 2) (e.g Taxifolin, and Naringenin). The conjugation between the $\mathrm{B}$ and $\mathrm{C}$ ring, is not as high as that of the rest of the molecule due to the non-planarity of B-ring with C-ring, therefore, B-ring can be seen as the weakest part of the delocalized system.

\subsection{Electronic properties of studied flavonoid molecules}

PM3 functional used in this study to calculate the electronic properties of the flavonoid studied molecules, such as ionization potential (IP), electron affinity (EA), electronegativity $(\chi)$, absolute hardness $(\eta)$, absolute softness $(\mathrm{S})$, electrophilic index $(\omega)$. The properties that are displayed in table 1 for each variable are computed based on the differences between the HOMO and LUMO energies of the neutral molecule and is known as orbital-vertical (Koopman's theorem). Table 1 represents the total energy, calculated energy levels of the HOMO, LUMO energy gap in (eV) and dipole moment of the investigated molecules. $\mathrm{E}_{\mathrm{HOMO}}$ is a quantum chemical parameter which is often associated with the electron donating ability of the molecule. High value of $\mathrm{E}_{\mathrm{HOMO}}$ is likely to a tendency of the molecule to donate electrons to appropriate acceptor molecule of low empty molecular orbital [22]. From Table 1, it can be clearly seen that the highest value of $\mathrm{E}_{\mathrm{HOMO}}-0.315292(\mathrm{eV})$ of morin indicates the better electron donating efficiency. The energy gap $\left(\Delta \mathrm{E}=\mathrm{E}_{\mathrm{LUMO}}-\mathrm{E}_{\mathrm{HOMO}}\right)$ is an important parameter as a function of reactivity of the flavonoid molecule towards the free radical. As $\Delta \mathrm{E}$ decreases the reactivity of the molecule increases were leading to increase in the electron donating efficiency of the molecule [23]. Lower values of the energy difference will render good antioxidant efficiency, because the energy to remove an electron from the last occupied orbital will be low [24]. The calculated energy of HOMO, LUMO and the energy gap were $-0.31958,-0.04009$ and $0.27949 \mathrm{eV}$ (Table 1), respectively for quercetin. Quercetin has the lowest $\Delta \mathrm{E}$ value than the other investigated flavonoid molecules in this study. The small value of energy gap and the distribution of $\pi$-bonding electron frontier orbital (HOMO and LUMO) were delocalized through the whole molecule (figure 2). A molecule with a low energy gap is generally associated with the high chemical activity and low kinetic stability and is termed soft molecule [25]. The investigated flavonoid molecule quercetin has highest softness value 7.15589 (table 1). This result showed that quercetin has the lowest energy gap and higher softness than the other investigated flavonoid molecule, this means that the molecule could behave a better antioxidant. The dipole moment is another parameter arise from the electronic distribution in a molecule and is the measure of polarity of a polar covalent bond. Fisetin have a highest value of dipole moment, but no significant relationship between dipole moment values and antioxidant efficiencies is noticed.

Ionization energy is a basic property of a chemical reactivity of atoms and molecule. High ionization energy value indicates high stability and chemical inertness and the lower value of ionization energy indicates high reactivity of atoms and molecule [26]. The low ionization energy $0.315292(\mathrm{eV})$ of morin compared to the other selected flavonoids indicates its high antioxidant efficiency. According to Sanderson's electronegativity equalization principle [27], the molecule chrysin with a high electronegativity quickly reaches equalization and hence low reactivity is expected. Table 1 show that the morin has low value of electronegativity among the investigated flavonoids and hence high reactivity was expected. The electrophilicity index $\omega$ is a measure of the stabilization in energy after a system accepts additional amount of electron charge from the other species [28]. The results show that naringenin was the strongest nucleophile, while chrysin was the strongest electrophile.

From the optimized flavonoid structures, the calculated excess charges on the atoms on the investigated flavonoids are shown in table 2. The highest atomic charges are available in the fourth position carbonyl oxygen atom. These theoretical values correlates with the metal binding properties of flavonoids as reported previously [29]. The earlier results suggested that binding at the 3-4 sites was stronger than at the 3'-4' sites. The complexation of iron containing one $\mathrm{Fe}$, Fe-quercetin binding strength at different sites has the order 3-4 > 4-5 > 3'-4'; while for complexes containing two $\mathrm{Fe}$ atoms, the complex with one $\mathrm{Fe}$ bound at the 3,4 site and the second Fe at the 3',4' site [30]. Table 2 showed the mulliken atomic charges of seven investigated flavonoids. The results demonstrate that the order of metal binding was based on mulliken atomic charges on the atom of flavonoid that is 4-5> 4-3> 3 '-4'. This order of metal chelation was possible only if flavonoids have C2-C3 double bond (e.g. Quercetin). In the absence of $\mathrm{C} 2-\mathrm{C} 3$ double bond the order of charges on atom was changed, hence the metal binding order was 4-3 > 4-5 > 3'-4' (e.g. taxifolin). Based on the presence and absence of $\mathrm{C} 2-\mathrm{C} 3$ double bond in the flavonoids, the metal binding preference was modified. 


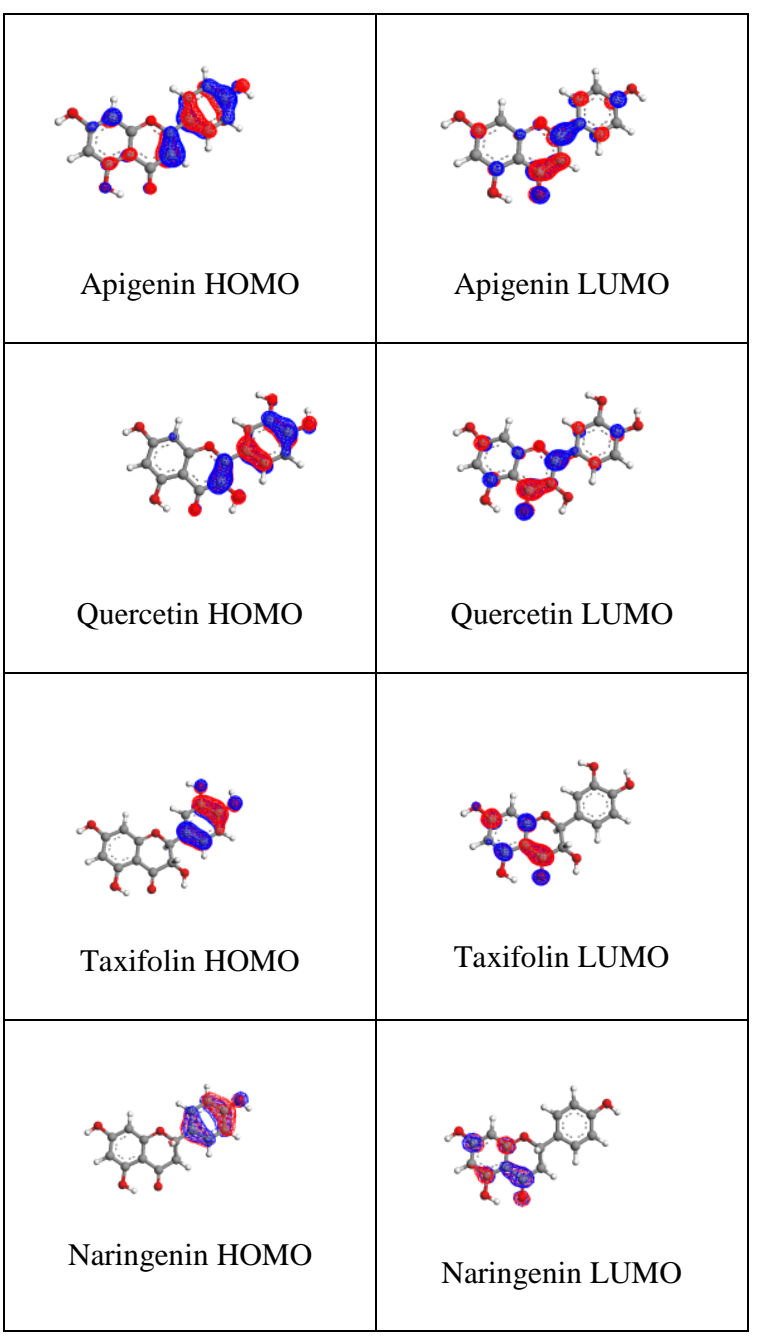

Figure 2. Charge distribution of the HOMO and LUMO in the optimized molecules

\section{5. $\mathrm{O}-\mathrm{H}$ bond distance and intramolecular hydrogen bonding}

Table 3 shows the hydroxyl bond distances of various $-\mathrm{OH}$ substituted flavonoids and their order of bond lengths. The observed results show that quercetin have the following order of bond lengths, $5-\mathrm{OH}>3-\mathrm{OH}>7-\mathrm{OH}>3^{\prime}-\mathrm{OH}>4^{\prime}-\mathrm{OH}$. In general weaker character of hydrogen bond was in agreement with the shorter $\mathrm{O}-\mathrm{H}$ bond distance for the $\mathrm{OH}$ group, while the longer the $\mathrm{OH}$ bond distance, the stronger the hydrogen bonding. As reported in the previous work [31] the quercetin $5-\mathrm{OH}$ have longer bond length than other $\mathrm{OH}$ groups, which may be due to stronger hydrogen bond interaction between 5$\mathrm{OH}$ and with the carbonyl group in C-ring. Similarly the interaction between 3-OH and 6'- $\mathrm{H}$ sites come next to the 5$\mathrm{OH}$ and $\mathrm{C}$ ring carbonyl group interaction. The 7-OH bond length is lower than $3-\mathrm{OH}$, this may be due to lack of any intramolecular hydrogen bonding through this position. The introduction of a hydroxyl in position 3 also weakens $5-\mathrm{OH}$ interaction with carbonyl group. The hydroxyl groups in Bring do not affect remarkably the interactions in $\mathrm{A}$ and $\mathrm{C}$ rings. The hydroxyl group bond distances in $\mathrm{B}$ ring are lower than $\mathrm{A}$ and $\mathrm{C}$ ring hydroxyl groups, discarding strong hydrogen bonding for B ring hydroxyl group, hence it have longer bond length than $\mathrm{A}$ and $\mathrm{C}$ ring $\mathrm{OH}$ bond. The intramolecular hydrogen bonding tendency was slightly altered for the flavonoids (taxifolin and fisetin) that have no $\mathrm{C} 2-\mathrm{C} 3$ double bond. The $\mathrm{OH}$ bond length and intramolecular hydrogen bond have a strong correlation among flavonoid molecule (Table 3).

Table 3 shows the bond distances of $2 \mathrm{C}-1^{\prime} \mathrm{C}$ of the entire optimized flavonoid molecules. The charge delocalization from $\mathrm{A}$ to $\mathrm{B}$ ring via $\mathrm{C}$ ring (through the $\mathrm{C} 2-\mathrm{C} 3$ double bond) can also be analysed here. The reported results in Table 3 shows that the charge delocalization between $\mathrm{A}$ and $\mathrm{B}$ rings are done through the double bond in $\mathrm{C}$ ring. The order of $2 \mathrm{C}-1$ ' $\mathrm{C}$ bond length for flavonoids are as follows; Taxifolin > Naringenin > Chrysin > Apigenin > Fisetin > Quercetin > Morin. The resonating electron current movements from ring $\mathrm{B}$ to $\mathrm{C}$ was through $2 \mathrm{C}-1$ ' $\mathrm{C}$ bond however, in the absence of $\mathrm{C} 2-\mathrm{C} 3$ double bond, the electron current movement was found to decrease. The bond distance between $2 \mathrm{C}-1$ ' $\mathrm{C}$ of all flavonoid are compared with their resonating efficiencies.

The electron current movement from $\mathrm{B}$ ring to $\mathrm{C}$ was restricted for $\mathrm{C} 2-\mathrm{C} 3$ double bond absent structures. As the flavonoid molecule taxifolin and naringenin were lack of $\mathrm{C} 2-\mathrm{C} 3$ double bond, the resonating electron current movement from $\mathrm{B}$ ring to $\mathrm{C}$ was restricted. HOMO, LUMO maps and the increase in $\mathrm{C} 2-\mathrm{C} 3$ bond length for taxifolin and naringenin is confirming the role of $\mathrm{C} 2-\mathrm{C} 3$ double bond in flavonoids. Hence the bond distance $2 \mathrm{C}-1{ }^{\prime} \mathrm{C}$ bond for these two flavonoids is found to increase compared with other flavonoids. The order of decrease in bond length next to toxifolin and naringenin was chrysin $>$ apigenin > fisetin > quercetin $>$ morin. And this order depends on the amount of electron current movement from ring $\mathrm{B}$ to $\mathrm{C}$ (Table 3). Chrysin does not have any hydroxyl group in B ring; hence it appears next to naringenin. Apigenin have one hydroxyl group in the B ring hence it comes next to chrysin. Fisetin, quercetin and morin each have two hydroxyl groups in the $\mathrm{B}$ ring, but in fisetin and quercetin that are in third and fourth positions. Electron releasing group in the adjacent position the electron current movement was decreased, hence morin $2 \mathrm{C}-1^{\prime} \mathrm{C}$ bond length lower than quercetin.

\subsection{BDE of $\mathrm{OH}$ in flavonoids}

Radical scavenging potency of flavonoids is mainly related to the presence of $\mathrm{OH}$ groups at specific positions on the flavonoid core. The minimal value of the Bond Dissociation Energy (BDE) of $\mathrm{OH}$ bonds indicates which $\mathrm{OH}$ group on the flavonoid core posses the most abstractable hydrogen, that is, which $\mathrm{OH}$ group is targeted for radical attack. Table 4 shows the BDE order of $\mathrm{OH}$ group in flavonoids. The BDE order of $\mathrm{OH}$ groups in quercetin is as follows 4'-O $<3$ '-O $<7-\mathrm{O}<$ $5-\mathrm{O}<3-\mathrm{O}$. This indicates that vicinal $\mathrm{OH}$ groups on the $\mathrm{B}$ ring are the preferred sites for hydrogen abstraction as seen in to quercetin most of the tabulated flavonoids has lower BDE for 4'-OH and 3'-OH presence in B ring. Similarly the higher $\mathrm{O}-\mathrm{H}$ BDE value is noted for 7-O < 5-O 3-O of flavonoids, may be due to interatomic hydrogen bond formed between fourth carbonyl and 5-OH and 3-OH groups. From the differences in the BDE value it is confirmed that reactivity of the $\mathrm{B}$ ring higher than that of A-ring.

\subsection{Spin density and their reactivity}

The more delocalized the spin density in the radical, the easier is the radical formed, and thus the lower is the BDE [32]. The spin population on the remaining $\mathrm{O}$-atom after $\mathrm{H}$ removal 
from $\mathrm{O}-\mathrm{H}$, appears to be delocalized. In the unrestricted scheme, the spin density is often considered to be a more realistic parameter and provides a better representation of the reactivity [33]. Spin density of flavonoid has been an important factor in the description of antioxidant behaviour [34].

The table 5 shows the difference in spin density of molecular and radical species of flavonoids. When comparing the molecular and radical flavonoid, the spin density value has lowered on all atoms in flavonoid molecule. The difference in spin density value of molecular and their radical flavonoids are analysed here. The decrease in spin density value for quercetin was $0.230,0.224,0.222,0.221$ and 0.201 for 4'-O', 3'-O' 7-O', 5-O' and 3-O' radical species respectively. This indicates that there was more delocalization for oxygen radical, formed in B-ring. The higher value of 5-O - and 3-O• may be due to hydrogen bonding of $3-\mathrm{OH}$ and $5-\mathrm{OH}$ groups with the fourth carbonyl group oxygen. Morin spin density values are in the decreasing order of 4'-O•, 5-O•, 7-O•, 2'-O• and 3 '-O•. The higher value of spin density difference for 4'$\mathrm{O} \cdot$ and lower value of spin density difference for $3-\mathrm{O}$ and the lower value for other $\mathrm{OH}$ was due to the position of $\mathrm{OH}$ groups in morin (2'-OH and 4'-OH). In the absence of C2-C3 double bond in naringenin and taxifolin the order of decrease in spin density was modified, because the resonating electron current movement from ring $\mathrm{B}$ to ring $\mathrm{C}$ was restricted. The $\mathrm{OH}$ group which have high spin density difference with - $\mathrm{O}$, will easily donate hydrogen to free radical species.

Table 6 shows the formation constant values for flavonoidmetal complexes. Mole fraction experiments revealed that a 1:1 stoichiometry for metal-flavonoid complexes. For a single flavonoid molecule, there are several possible sites that could bind a metal atom. The possible binding site for apigenin, naringenin and chrysin was fourth carbonyl oxygen and 5hydroxyl oxygen. Their formation constant values with $\mathrm{Pb}, \mathrm{Bi}$ and $\mathrm{Cd}$ metals are reported.

Fisetin have two possible binding sites one at $4^{\text {th }}$ carbonyl oxygen and 3-hydroxy oxygen, another one was 3'-O and 4'-O groups. The formation constant value of fourth carbonyl oxygen and 3-hydroxyl oxygen was lower than 3'-O and 4'-O formation constant. Formation constant values are well correlated with the mulliken atomic charges on atoms in molecules (Table 2). Morin also have two possible binding sites one is $4^{\text {th }}$ carbonyl group oxygen and $3-\mathrm{OH}$ oxygen another one is $4^{\text {th }}$ carbonyl group oxygen and 5-OH oxygen. The formation constant value of $4^{\text {th }}$ carbonyl and 5-OH was lower than $4^{\text {th }}$ carbonyl oxygen $3-\mathrm{OH}$ sites. These results are well correlated with the mulliken atomic charges of atoms in morin (Table 2). 5-OH oxygen have higher charges $(-0.2698)$ than the 3-OH oxygen charge $(-0.2353)$. Quercetin have three possible sites for metal chelation, $4^{\text {th }}$ carbonyl oxygen \& $3-\mathrm{OH}, 4^{\text {th }}$ carbonyl oxygen \& 5-OH and 3'-OH \& 4'-OH. The formation constant values are in the order of $4=\mathrm{O} \& 5-\mathrm{O}<$ $4=\mathrm{O} \& 3-\mathrm{O}<3$ ' $\mathrm{O} \&$ 4'-O. This order of formation constant correlate with mulliken atomic charges, 5-OH oxygen charge

Table-1. The total energy, HOMO, LUMO, $\triangle \mathrm{E}$ (ev) and the dipole moment (Debye) for the studied molecule

\begin{tabular}{|l|l|l|l|l|l|l|l|}
\hline Parameters & Quercetin & Morin & Fisetin & Apigenin & Chrysin & Taxifolin & Naringenin \\
\hline$\Delta \mathrm{H}_{\mathrm{f}}$ & -224.373 & -223.8852 & -175.309 & -142.195 & -96.6987 & -237.1898 & -158.8035 \\
\hline HOMO & -031958 & $\mathbf{- 0 . 3 1 5 2 9 2}$ & -0.31582 & -0.33533 & -0.33871 & -0.327540 & -0.341074 \\
\hline LUMO & -0.04009 & -0.034085 & -0.03434 & -0.03696 & -0.03815 & -0.032046 & -0.022956 \\
\hline $\begin{array}{l}\text { Dipole Moment } \\
\text { (Debye) }\end{array}$ & 2.758272 & 2.2798268 & $\mathbf{3 . 8 5 0 3 0 5}$ & 2.576055 & 2.955009 & 2.488736 & 2.169745 \\
\hline
\end{tabular}

was higher than 3-OH oxygen charge, hence 5-OH with metal formation constant is lower in value. Taxifolin as similar to quercetin three possible chelation sites, but absence of C2-C3 double bond the formation constant order has changed $4=\mathrm{O} \&$ $3-\mathrm{O}<4=\mathrm{O} \& 5-\mathrm{O}<3$ '-O \& 4'-O. This change in order was and also the structural property of taxifolin. Taxifolin has no conjugation, due to the absence of $\mathrm{C} 2-\mathrm{C} 3$ double bond, hence 3-O has higher charge than 5-O. Some studies report that 3'4' site is the first chelation site [35]. This may be due to different solvent conditions (acidic or basic). The results suggest that metal binding site order was 4-5, 4-3 and 3' -4 ' in the presence of $\mathrm{C} 2-\mathrm{C} 3$ double bond, in the absence of $\mathrm{C} 2-\mathrm{C} 3$ double bond the order was 4-3, 4-5 and 3' -4 '.

\section{CONCLUSION}

The results of semiempirical methods are usually good in a qualitative sense and very useful in the comparison of data obtained for structurally related compounds. A systematic computational study on the properties of flavonoids has been carried out to a deeper insight into their molecular properties. Quantum chemical parameters such as $\mathrm{E}_{\text {Hомо }}, \mathrm{E}_{\mathrm{LUMO}}$, energy gap $(\Delta \mathrm{E})$, hardness $(\eta)$, softness $(\mathrm{S})$, electron affinity (EA), ionization potential (IP), absolute electronegativity $(\chi)$ and electrophilicity index $(\omega)$ were calculated. The BDE value of $\mathrm{OH}$ bond is an important parameter in evaluating antioxidant action, because weaker the $\mathrm{O}-\mathrm{H}$ bond the faster the radical inactivation. The present semiempirical values clearly demonstrate that $\mathrm{H}$-transfer from B-ring is easier than A-ring and C-ring.

The optimized structures of metal-flavonoid complexes were investigated. The study on complexation of metal with flavonoid in gas phase shows that chelation property depends on charge on the chelating site of flavonoid. The mulliken atomic charge data implicate that 3-OH \& 4-carbonyl, 5-OH \& 4-carbonyl and catechol structural units are with chelating power. The orders of chelating efficiency of flavonoid depend on charge on the chelating site. The binding energy for the metal atom to a single flavonoid (quercetin) molecule demonstrates that 3-hydroxyl \& 4-carbonyl group is optimal chelation site, followed by 4-5 and 3'-4' sites. In the absence of C2-C3 double bond, flavonoid (taxifolin) binding site with metal was found to be 5-4, 3-5 and 3'-4'sites.

\section{ACKNOWLEDGEMENTS}

This work was supported by the research grants from the UGC (University Grants Commission) major research project No.: F. No. 39-731/2010 (SR) Government of India. The corresponding author (MR) is grateful to UGC (New Delhi) for providing financial assistance. The authors are thankful to principal and the management of N.M.S.S.Vellaichamy Nadar College for providing laboratory facilities. due to higher mulliken atomic charge on the $3-\mathrm{OH}$ oxygen 


\begin{tabular}{|l|l|l|l|l|l|l|l|}
\hline$\Delta \mathrm{E}(\mathrm{eV})$ & $\mathbf{0 . 2 7 9 4 9}$ & 0.281207 & 0.28148 & 0.29837 & 0.30056 & 0.295494 & $\mathbf{0 . 3 1 7 2 1 8}$ \\
\hline $\begin{array}{l}\text { Ionization } \\
\text { Potential }(\mathrm{I})(\mathrm{eV})\end{array}$ & 0.31958 & $\mathbf{0 . 3 1 5 2 9 2}$ & 0.31582 & 0.33533 & 0.33871 & 0.327540 & $\mathbf{0 . 3 4 0 1 7 4}$ \\
\hline $\begin{array}{l}\text { Electron Affinity } \\
(\mathrm{A})\end{array}$ & $\mathbf{0 . 0 4 0 0 9}$ & 0.0340085 & 0.03434 & 0.03696 & 0.03815 & 0.032046 & 0.022956 \\
\hline $\begin{array}{l}\text { Chemical } \\
\text { Potential }(\mu)(\mathrm{eV})\end{array}$ & -0.17983 & -0.174688 & -0.17508 & -0.18614 & -0.18843 & -0.17979 & -0.181565 \\
\hline $\begin{array}{l}\text { Electronegativity } \\
(\chi)(\mathrm{eV})\end{array}$ & 0.179835 & $\mathbf{0 . 1 7 4 6 8 8 5}$ & 0.17508 & 0.186145 & $\mathbf{0 . 1 8 8 4 3}$ & 0.179793 & 0.181565 \\
\hline $\begin{array}{l}\text { Global Hardness } \\
(\eta)\end{array}$ & 0.139745 & 0.140603 & 0.14074 & 0.149185 & 0.15028 & 0.14774 & $\mathbf{0 . 1 5 8 6 0 9}$ \\
\hline $\begin{array}{l}\text { Global Softness } \\
(\mathrm{S})\end{array}$ & $\mathbf{7 . 1 5 5 8 9}$ & 7.11222 & 7.105530 & 6.703086 & 6.654245 & 6.768326 & 6.304812 \\
\hline $\begin{array}{l}\text { Electrophilicity } \\
(\omega)\end{array}$ & 0.115708 & 0.108518 & 0.108899 & 0.116130 & $\mathbf{0 . 1 1 8 1 3 2}$ & 0.109394 & $\mathbf{0 . 1 0 3 9 2 1 7}$ \\
\hline
\end{tabular}

Table -2. PM3 optimized flavonoids mulliken atomic charges

\begin{tabular}{|l|c|c|c|c|c|c|c|c|c|c|}
\hline Flavonoids & $1-\mathrm{O}$ & $3-\mathrm{O}$ & $4=\mathrm{O}$ & $5-\mathrm{O}$ & $7-\mathrm{O}$ & $2^{\prime}-\mathrm{O}$ & $3^{\prime}-\mathrm{O}$ & $4{ }^{\prime}-\mathrm{O}$ & $\mathrm{C}-2$ & $\mathrm{C}-3$ \\
\hline Quercetin & -0.1038 & -0.2286 & -0.406 & -0.2661 & -0.2341 & & -0.257 & -0.233 & 0.1122 & -0.1299 \\
\hline Taxifolin & -0.2051 & -0.3118 & -0.3772 & -0.2655 & -0.2406 & & -0.2531 & -0.2538 & 0.0752 & -0.0869 \\
\hline Fisetin & -0.1060 & -0.2312 & -0.3571 & & -0.2335 & & -0.2576 & -0.2339 & 0.0959 & -0.01306 \\
\hline Chrysin & -0.1114 & & -0.3935 & -0.2705 & -0.2357 & & & & 0.1764 & -0.4189 \\
\hline Apigenin & -0.1125 & & -0.3957 & -0.2709 & -0.2357 & & & -0.2331 & 0.1885 & -0.4283 \\
\hline Naringenin & -0.2117 & & -0.3753 & -0.2694 & -0.2427 & & & -0.2446 & 0.0923 & -0.3581 \\
\hline Morin & -0.0155 & -0.2427 & -0.5045 & -0.2698 & -0.2432 & -0.244 & & -0.2368 & 0.1271 & -0.0934 \\
\hline
\end{tabular}

Table-3 Bond Distances in $\left(\mathrm{A}^{\circ}\right)$ after optimized with PM3 method, in gas phase

\begin{tabular}{|l|l|l|l|l|l|l|l|}
\hline & $5-\mathrm{OH}$ & $3-\mathrm{OH}$ & $7-\mathrm{OH}$ & $3^{\prime}-\mathrm{OH}$ & $4^{\prime}-\mathrm{OH}$ & $2^{\prime}-\mathrm{OH}$ & $2 \mathrm{C}-1^{\prime} \mathrm{C}$ \\
\hline Quercetin & 0.96644 & 0.95215 & 0.951802 & 0.950606 & 0.950224 & & 1.472481 \\
\hline Taxifolin & 0.965322 & 0.951273 & 0.951846 & 0.950548 & 0.95009 & & $\mathbf{1 . 5 1 5 0 2 7}$ \\
\hline Fisetin & & 0.950084 & 0.951488 & 0.950013 & 0.950198 & & 1.472724 \\
\hline Chrysin & 0.967599 & & 0.961752 & & & & 1.475984 \\
\hline Apigenin & 0.967584 & & 0.951715 & & 0.951360 & & 1.473511 \\
\hline Naringenin & 0.965844 & & 0.951759 & & 0.951200 & & $\mathbf{1 . 5 1 2 0 2 4}$ \\
\hline Morin & 0.966635 & 0.951938 & 0.951725 & & 0.951426 & 0.951669 & 1.462769 \\
\hline
\end{tabular}

Table-4 Calculated Bond dissociation energy (BDE) orders at the various $\mathrm{OH}$ position in flavonoids

\begin{tabular}{|c|c|c|c|c|c|c|c|c|}
\hline Quercetin & 4 '-O & $<$ & $3 '-O$ & $<$ & $7-\mathrm{O}$ & $<$ & $5-\mathrm{O}$ & $<\quad 3-\mathrm{O}$ \\
\hline Morin & $4^{\prime}-\mathrm{O}$ & $<$ & $7-\mathrm{O}$ & $<$ & 2'-O & $<$ & $5-\mathrm{O}$ & $3-\mathrm{O}$ \\
\hline Apigenin & $7-\mathrm{O}$ & $<$ & $4^{\prime}-\mathrm{O}$ & $<$ & $5-\mathrm{O}$ & & & \\
\hline Chrysin & $7-\mathrm{O}$ & $<$ & $5-\mathrm{O}$ & & & & & \\
\hline Fisetin & $7-\mathrm{O}$ & $<$ & $4 '-\mathrm{O}$ & $<$ & 3'-O & $<$ & $3-\mathrm{O}$ & \\
\hline Naringenin & 4 '-O & $<$ & $7-\mathrm{O}$ & $<$ & $5-\mathrm{O}$ & & & \\
\hline Taxifolin & 4 '-O & $<$ & $3 '-O$ & $<$ & $7-\mathrm{O}$ & $<$ & $5-\mathrm{O}$ & $3-\mathrm{O}$ \\
\hline
\end{tabular}


Table-5 Differences in mulliken atomic charges, after removal of -OH hydrogen atom from the neutral flavonoids.

\begin{tabular}{|c|c|c|c|c|c|c|c|c|}
\hline Quercetin & $\begin{array}{l}4^{\prime}-\mathrm{O} \\
0.230\end{array}$ & $>$ & $\begin{array}{l}3 '-\mathrm{O} \\
0.224 \\
\end{array}$ & $>$ & $\begin{array}{c}7-\mathrm{O} \\
0.222 \\
\end{array}$ & $>$ & $\begin{array}{r}5-\mathrm{O} \\
0.221 \\
\end{array}$ & $\begin{array}{r}3-\mathrm{O} \\
0.201 \\
\end{array}$ \\
\hline Morin & $\begin{array}{l}4^{\prime}-\mathrm{O} \\
0.224\end{array}$ & $>$ & $\begin{array}{l}5-\mathrm{O} \\
0.224\end{array}$ & $>$ & $\begin{array}{l}7-\mathrm{O} \\
0.222\end{array}$ & $>$ & $\begin{array}{r}2 '-\mathrm{O} \\
0.217\end{array}$ & $\begin{array}{r}3-\mathrm{O} \\
0.204\end{array}$ \\
\hline Apigenin & $\begin{array}{l}5-\mathrm{O} \\
0.224\end{array}$ & $>$ & $\begin{array}{l}7-\mathrm{O} \\
0.222\end{array}$ & $>$ & $\begin{array}{l}4^{\prime}-\mathrm{O} \\
0.218\end{array}$ & & & \\
\hline Chrysin & $\begin{array}{l}7-\mathrm{O} \\
0.218 \\
\end{array}$ & $>$ & $\begin{array}{l}5-\mathrm{O} \\
0.021 \\
\end{array}$ & & & & & \\
\hline Fisetin & $\begin{array}{l}-\mathrm{O} \\
0.221 \\
\end{array}$ & $>$ & $\begin{array}{l}\text { 4'-O } \\
0.213 \\
\end{array}$ & $>$ & $\begin{array}{l}3 '-\mathrm{O} \\
0.211 \\
\end{array}$ & $>$ & $\begin{array}{l}3-\mathrm{O} \\
0.202\end{array}$ & \\
\hline Naringenin & $\begin{array}{l}5-\mathrm{O} \\
0.224\end{array}$ & $>$ & $\begin{array}{l}7-\mathrm{O} \\
0.222\end{array}$ & $>$ & $\begin{array}{l}4^{\prime}-\mathrm{O} \\
0.216\end{array}$ & & & \\
\hline Taxifolin & $\begin{array}{l}3-\mathrm{O} \\
0.239\end{array}$ & $>$ & $\begin{array}{l}\text { 3'-O } \\
0.230 \\
\end{array}$ & $>$ & $\begin{array}{r}4 '-\mathrm{O} \\
0.229 \\
\end{array}$ & $>$ & $\begin{array}{l}5-\mathrm{O} \\
0.225\end{array}$ & $\begin{array}{l}>\quad 7-\mathrm{O} \\
0.224\end{array}$ \\
\hline
\end{tabular}

Table-6 Formation constant values of flavonoid-metal complexes calculated by MM(UFF) method

\begin{tabular}{|l|l|l|l|}
\hline Metal chelating sites & Formation constant kcal/mol & Formation constant kcal/mol & Formation constant kcal/mol \\
\hline $\begin{array}{l}\text { Apigenin } \\
\text { 4keto,5hydroxy }\end{array}$ & Apigenin-pb & & \\
\hline Chrysin & 67.04354605 & Apigenin-Bi & Apigenin-Cd \\
4keto, 5hydroxy & Chrysin-pb & Chrinsin-Bi & 62.60301647 \\
\hline Fisetin & 66.79615555 & 54.85756666 & Chrysin-Cd \\
4keto, 3hydroxy & Fisetin-Pb & Fisetin-Bi & 62.44283754 \\
\hline Fisetin & 69.05617333 & 58.01115621 & Fisetin-Cd \\
3'4'hydroxy & Fisetin-Pb & Fisetin-Bi & 68.41067366 \\
\hline Morin & 69.61364541 & 58.88701525 & Fisetin-Cd \\
3hydroxy 4keto & Morin-Pb & Morin-Bi & 68.36815317 \\
\hline Morin & 71.31808457 & 60.12149712 & Morin-Cd \\
5hydroxy 4keto & Morin-Pb & Morin-Bi & 70.74884584 \\
\hline Naringenin & 70.38913704 & 58.36616423 & Morin-Cd \\
5hydroxy 4keto & Naringenin-Pb & Naringenin-Bi & 66.01514389 \\
\hline Quercetin & 51.34232137 & 42.38606897 & Naringenin-Cd \\
3hydroxy 4keto & Quercetin-Pb & Quercetin-Bi & 47.31938598 \\
\hline Quercetin & 70.82007459 & 59.59937902 & Quercetin-Cd \\
5hydroxy 4keto & Quercetin-Pb & Quercetin-Bi & 70.25781055 \\
\hline Quercetin & 69.98430509 & 57.96043958 & Quercetin-Cd \\
3',4'-hydroxy & Quercetin-Pb & Quercetin-Bi & 65.63366226 \\
\hline Taxifolin & 71.32394833 & 60.59483893 & Quercetin-Cd \\
3hydroxy 4keto & Taxifolin- $\mathrm{Pb}$ & Taxifolin-Bi & 70.07719294 \\
\hline Taxifolin & 50.90080964 & 40.01854597 & Taxifolin-Cd \\
5hydroxy 4keto & Taxifolin- $\mathrm{Pb}$ & Taxifolin-Bi & 49.52627828 \\
\hline Taxifolin & 53.09607002 & 44.08780535 & Taxifolin-Cd \\
3'4'-hydroxy & Taxifolin- $\mathrm{Pb}$ & Taxifolin-Bi & 49.11226105 \\
\hline & 63.35768849 & 52.64166156 & Taxifolin-Cd \\
\hline
\end{tabular}

Table-7 Experimental UV -Visible spectrophotometer data of flavonoids in Phosphate buffer ( $\mathrm{pH} 7.4$ )

\begin{tabular}{|l|c|c|c|}
\hline \multicolumn{1}{|c|}{ Flavonoids } & B ring (nm) & A ring (nm) & C ring (nm) \\
\hline Quercetin & 379 & 320 & 270 \\
Naringenin & 322 & 225 & -- \\
Morin & 392 & 269 & 222 \\
Chrysin & 350 & 272 & 271 \\
Apigenin & 357 & 297 & 249 \\
Fisetin & 371 & 320 & --- \\
Taxifolin & 326 & 224 & \\
\hline
\end{tabular}

\section{REFERENCES}

[1] Guohua, C., Emin, S., and Ronald, L. 1997. Free Radic. Biol. Med. 22 (1997) 749-760
[2] Jovanovic, S.V., Steenken, M S., Tosic, M., Marjanovic, B., and Simic, M.G. 1994. Flavonoids as antioxidants. J. Am. Chem. Soc. 116 (1994) 4846-4851. 
[3] Cotelle, N., 2001. Role of flavonoids in oxidative stess. Curr. Top. Med. Chem. 1 (2001) 569-590.

[4] Antonczak, S., 2008. Electronic description of four flavonoids revisited by DFT method. J. Mol. Struc. Theochem. 856 (2008)38-45.

[5] Lameira, J., Alves, J., Moliner, C.N., and Silla, V., 2006. A density functional study of flavonoi compounds with anti-HIVactivity. Eur. J. Med. Chem. 41 (2006) 616-623.

[6] Harborne. J.B., and Grayer, R., 1988. The flavonoidsAdvances in Research since 1980, Chapman and Hall, London, 1988

[7] Mira, L., Fernandez, M.T., Santos, M., Rocha, R., Florenico, M.H., and Jennings, K.R., 2002. Free Radic. Res. 36 (2002) 1199-1208

[8] Korkina, L.G., and Ajanas'ev, I.B., in: H. Sies (Ed.) Antioxidants in Disease mechanisms and therapy vo. 38. Academic press, New York. 1997, p.151.

[9] Pannola, A., Rice-Evans, C., Halliwell, B., and Sing, S., 1997. Biochem. Biophys. Res. Commun. 232 (1997) 164.

[10] Halliwell, B. A., and Gutteridge, M.C., 1984. Biochem,. J. 219 (1984) 1.

[11] Minotti, G., and Aust, S. D., 1989. Chem. Biol. Interact. 71 (1989) 1.

[12] Le Nest, G., Caille, O., Woudstra, M., Roche, S., Burlat, B., Belle, V., Guigliarelli, B., and Lexa, D., 2004. Inorg. Chim. Acta, 357 (2004) 2027.

[13] Ren, J., Meng, S., Lekka ChE, and Kaxiras E., 2008. Complexation of flavonoids with iron: Structure and optical signaturese. J. Phys. Chem. B., 112 (2008) 18451850 .

[14] Rajendran, M., Mahalakshmi, M., Ramya, R., and Devapiriam, D., 2011. A semi-empirical study of flavone compounds with antioxidant efficiency, African Journal of Pharmacy and Pharmacology 5 (2011) 21402144.

[15] ArgusLab 4.0.1 Mark A. Thompson Planaria Software LLC, Seattle, WA. http://www.arguslab.com

[16] Dewar, M.J.S., Zoobisch, E. G., Healy, E. F. and Stewart, J. J. P., 1985. AM1: A new general purpose Quantum mechanical molecular model. J. Am. Chem. Soc. 107 (1985) 3902-3910.

[17] Fernandez, M.T., and Mira, L., 2002. J. Inorg. Biochem. 92 (2002) 105-115.

[18] Wright, J.S., Johnson, E.R., and Dilabio, G.A., 2001. Predicting the activity of phenolic antioxidants: theoretical method, analysis of substituent effects, and application to major families of antioxidants. J. Am. Chem. Soc. 123 (2001) 1173-1183.

[19] Anouar, E.H., Giershner, J., Duroux, J., and Trouillas, P., 2012. UV/Visible spectra of natural polyphenols: A time- dependent density functional theory study. Food Chemistry, 131 (2012) 79-89.

[20] Harborne, J.B., Mabry, T.J., and Mabry, H., 1975 The flavonoids. London: Chapman and Hall.

[21] Rice-Evans, C., Miller, N., and Paganga, G., 1996. Structure-antioxidant activity relationships of flavonoids and phenolic acids. Free Radical Biology and Medicine, 20 (1996) 933-956.

[22] Gece, G., and Bilgic, S., 2009. Corros. Sci., 51 (2009) 1876.

[23] Awad, M.K., Mustafa, M.R., and Abo Elnga, M.M., 2010. J. Mol. Struct.(Theochem) 959 (2010) 66

[24] Obot, I.B., Obi-Egbedi, N.O., Umoren, S.A., 2009. Int. J. Electrochem. Sci. 4 (2009) 863.

[25] Fleming, I., 1976 Frontier orbitals and organic chemical reactions, John Wiley and sons, New York, 1976.

[26] Chakraborty, T., and Ghosh, D.C., 2010. Mol. Phys. 108 (2010) 2081.

[27] Geerlings, P., and De Profit, F., 2002. Int. J. Mol. Sci. 3 (2002) 276

[28] Liu, S., 2005. J. Chem. Sci. 117 (2005) 477.

[29] Ren, J., Meng, S., ChE Lekka, Kaxiras, E., 2008. Complexation of flavonoids with iron: Structure and optical signatures, J. Phys. Chem. B, 112 (2008) 18451850.

[30] Pawlak, K., Bylwa, W., Jazurek, B., Matlawska, I., Sikorska, M., Manikowski, H., and Bialek-Bylka, G., 2010. Antioxidant activity of different polarity flavonoids by modified ABTS cation radical decolourization assay and EPR technique, Acta Biologica Cracoviensia Series Botanica, 52 (2010) 97 104

[31] Aparicio, S., 2010. A systematic computational study of flavonoids, Int. J. Mol. Sci. 11 (2010) 2017-2038.

[32] Parkinson, C.J., Mayer, P.M., \& Radom, L., 1999. Assesement of theoretical procedures for the calculation of reliable radical stabilization energies. J. Chem. Soc. Perkin Trans. 2, 11 (1999) 2305-2313.

[33] Szabo, A., and Oslund, N.S., 1982 Modern quantum chemistry: Introduction to advanced electronic structure theory, New-York: Dover Publication.

[34] Leopoldini, M., Marino, T., Russo, N., and Toscano, M., 2004. Density functional computation of the energetic and spectroscopic parametes of quercetin and its radicals in the gas phase and in solvent, Theoretical Chemistry Accounts. 111 (2004) 210-216.

[35] Engelmann, M.D., Hutcheson, R., and Cheng, I.F., 2005. Stability of ferric complexes with 3Hydroxyflavone(flavonol),5,7-dihydroxyflavone (chrysin), and 3',4'-dihydroxyflavone. J. Agri. Food Chem. 53 (2005) 2953. 